\title{
Pengembangan Aset Tiga Dimensi Berbasis Photo-Realism untuk VR-Patient Room (Studi Kasus Rawat Inap RSI Jemursari)
}

\author{
Rizqi Putri Nourma Budiarti ${ }^{*}$ dan Fajar Annas Susanto ${ }^{1}$ \\ ${ }^{1}$ Sistem Informasi, Fakultas Teknik, Universitas Nahdlatul Ulama Surabaya, Surabaya \\ *Corresponding Author \\ E-mail: rizqi.putri.nb@unusa.ac.id
}

\begin{abstract}
Abstrak
Perkembangan informasi pada suatu rumah sakit sangat cepat berkembang, dimana rumah sakit ingin memberikan pelayanan berupa informasi mengenai rumah sakit tersebut dengan menggunakan teknologi Virtual Reality. Begitu juga dengan Rumah Sakit Islam Jemursari, dimana sedang mengembangkan aplikasi VR-Patien Room. Untuk pengembangan VR-Patient Room diperlukan beberapa aset berupa perangkat atau peralatan yang berada di rumah sakit tersebut. Pada penelitian ini, dikembangkan aset menggunakan metode photo-realism. Aset dibangun dengan mengikuti kriteria dari photo-realism, mengikuti skala ukuran dan menggunakan aplikasi 3D. Aset yang dibangun antara lain: kasur pasien, furniture (meja, sofa tamu, jam dinding), tempat sampah, dan meja pasien hingga toilet dan shower. Setelah seluruh aset dibangun dilakukan ekperimen dengan metode survey untuk mengukur tingkat realistic dari aset. Dari eksperimen tersebut didapat tingkat realistik dari aset yang dibuat memiliki nilai rata-rata diatas 3.7 dari skala 5 , dimana artinya $3 \mathrm{D}$ aset yang dibuat sudah mendekati benda dengan karakteristik photo-realism.
\end{abstract}

Kata Kunci: $3 D$ aset, VR Patient-Room, photo-realism.

\begin{abstract}
The development of information in a hospital is very fast growing, where the hospital wants to provide services in the form of information about the hospital using Virtual Reality technology. Likewise with Jemursari Islamic Hospital, which is developing the VR-Patien Room application. For the development of $V R$-Patient Rooms, several assets are needed in the form of devices or equipment located in the hospital. In this study, assets were developed using the photo-realism method. Assets are built by following the criteria of photo-realism, following the scale of size and using $3 D$ applications. Assets built include: patient beds, furniture (tables, guest sofas, wall clocks), trash bins, and patient desks to the toilet and shower. After all assets are built, an experiment is conducted using survey methods to measure the realistic level of assets. From these experiments obtained a realistic level of the assets made have an average value above 3.7 from a scale of 5, which means that the $3 D$ assets made are approaching objects with photo-realism characteristics.
\end{abstract}

Keywords: 3D Asset, VR Patient-Room, photo-realism.

\section{PENDAHULUAN}

Teknologi informasi biasa digunakan untuk membantu banyak orang dan bahkan di era modern ini teknologi sudah tersebar dimanapun, baik dibidang pendidikan, militer, pertanian bahkan kesehatan. Di rumah sakitpun, teknologi sangat berperan penting dalam menjaga kestabilan pasien yang sedang dirawat. Selain digunakan untuk kesehatan, teknologi dapat digunakan juga untuk berbagi informasi. Teknologi yang dapat digunakan untuk menampilkan 
informasi antara lain Virtual Reality. Teknologi Virtual Reality memerlukan aset berupa model tiga dimensi (3D). Penggunaan teknologi virtual reality, sering dipakai untuk pembuatan dan pengembangan game misalkan mengatur perilaku NPC (Non-Player Character) pada lingkungan virtual salah satunya NSGA-II dengan pengembangan algoritma genetika untuk evolusi dinamis pada NPC (aditama, 2019). Di dalam lingkungan virtual inilah, pemetaan tiga dimensi biasanya dilakukan.

Pemetaan tiga dimensi dalam realitas maya adalah salah satu yang sedang popular dan dapat diterapkan dimanapun, teknologi semacam ini telah ditemukan bertahun-tahun lalu dan masih dikembangkan hingga saat ini. Pada saat ini bahkan ada berbagai macam aplikasi yang dapat membantu untuk membuat atau membangun desain 3 dimensi dan menjadikannya dalam bentuk realitas maya. Dalam penelitian ini, diperlukan pembuatan 3D Aset untuk pemetaan ruangan dan aplikasi Blender dirasa paling sempurna karena berlisensi terbuka dapat mencakup semua hal dan mudah diunduh.

Rumah sakit sebenarnya sangat membutuhkan teknologi virtual reality untuk memetakan keseluruhan rumah sakit, khususnya pada ruang rawat inap, karena pada ruang rawat inap semua fasilitas hampir sama dan lokasi ruang rawat inap juga terkadang membingungkan. Sebagai contoh, di rumah sakit dengan area lokasi yang luas seperti Rumah Sakit Islam Jemursari dengan dimana lokasi ruang rawat inap dan penamaan ruang rawat inap pun bisa hampir sama sehingga dibutuhkan petunjuk digital yang tepat. Selain itu penggunaan pemetaan ruangan tiga dimensi realita maya juga dapat menaikkan nama rumah sakit serta meningkatkan jumlah investor karena dengan menggunakan teknologi tersebut dapat memberikan kesan modern.

Dengan adanya sistem ini maka diharapkan pada pengembangan desain interaktif untuk $V R$ Patient Room ini dapat memberikan gambaran ruangan rawat inap dan fasilitas yang didapatkan pasien sehingga memudahkan pasien mendapatkan gambaran yang detail sesuai dengan keadaan yang sebenarnya. Hal inilah yang diharapkan dapat membantu pasien dan pihak rumah sakit dalam menjelaskan penggambaran ruangan pasien serta penghematan waktu dengan adanya teknologi ini.

\section{METODOLOGI}

\subsection{D Building Information Management (BIM) Untuk Fasilitas Rumah Sakit.}

Tiga Dimensi (3D) merupakan sesuatu yang memiliki panjang, lebar dan tinggi, seperti semua benda yang memiliki bentuk di dunia nyata. Pada dasarnya, manusia dapat membedakan mana 3 dimensi mana 2 dimensi karena manusia memiliki persepsi 3 dimensi atau yang lebih dikenal dengan persepsi kedalaman. Pada persepsi kedalaman, apabila kita melihat dalam mata kita bayangan diterima dalam bentuk 2 dimensi secara keseluruhan tetapi ketika diproses di otak kita, gambar tersebut berubah menjadi 3 dimensi itulah kenapa pada saat melihat bioskop 3 dimensi biasanya penonton hanya diberi kacamata merah dan biru. Hal itu digunakan untuk membantu otak mengolah bayangan film menjadi objek 3 dimensi. Dari teknologi 3D tersebut dapat dibangun sebuah aplikasi yang mampu memberikan informasi kepada pengguna dalam rangka menginformasikan suatu fungsi dari bangunan, teknologi tersebut bernama Building Information Management (BIM).

Yu-Cheng Lin dkk, melakukan penelitian dengan membangun BIM untuk sebuah rumah sakit untuk penyakit kanker (Yu-Chen Lin, 2018). Pada penelitian ini yang dilakukan juga menggunakan teknologi yang sama namun digunakan untuk ruang rawat inap Rumah Sakit Islam Jemursari Surabaya. Dalam hal ini, untuk membangun suatu visualisasi ruangan yang bermanfaat 
buat masyarakat khususnya di area lingkungan rumah sakit, khususnya pasien rumah sakit agar dalam melawan penyakitnya pasien tetap dalam kondisi semangat, aman, nyaman dan kondusif didukung oleh lingkungan. Dengan penggunaan teknologi 3D, khususnya untuk membangun desain ruangan interaktif untuk VR-Patient Room sehingga dapat membantu pasien dalam memilih ruangan perawatan untuk rawat inap di Rumah Sakit.

\subsection{Virtual Reality (VR)}

Realitas maya adalah kegunaan teknologi computer dalam membuat simulasi sesuatu baik itu benda, pemandangan atau apapun dalam bentuk 3 dimensi, untuk lebih dapat terlihat bedanya dalam realitas maya pengguna wajib menggunakan alat tertentu yang menempel pada mata yang ditujukan agar pengguna dapat merasakan sensasi berada dalam dunia berbeda, semua itu dengan cara mensimulasi sebanyak mungkin indera seperti penglihatan, pendengaran sentuhan, bahkan bau.

Dunston., dkk. membangun sebuah aplikasi berbasis Virtual Reality(VR) dengan membangun seluruh fasilitas baik berupa furniture maupun perangkat/peralatan rumah sakit (Dunston, 2011). Hal tersebut kami lakukan juga pada penelitian ini, karena hal tersebut dibutuhkan untuk mengisi aset dari aplikasi VR. Chan, W.Y., dkk, melakukan riset dengan membangun Virtual Reality untuk simulasi fasilitas Rumah Sakit sebagai training perawat (Chan, 2018). Jonathan Linowes menjelaskan berbagai project yang bisa dilakukan pada Virtual Reality dalam bukunya (Linowes, 2015). Sedangkan Pavol K., dkk. telah membuat Virtual Reality dengan pendekatan innovative approach pada penggunaan Virtual Reality untuk design objek Interior (Pavol, 2017). Penggunaan lainnya pada virtual reality, S. Bayona mengimplementasikan penggunaan teknologi ini pada sektor healthcare (Bayona, 2016).

\subsection{Blender}

Blender merupakan aplikasi untuk membuat objek 3 dimensi yang gratis dan open source (Blender, 2019). aplikasi ini merupakan salah satu aplikasi terbaik untuk membuat objek 3 dimensi, kelebihan dari blender adalah program yang ringan tapi sangat powerfull.

Aplikasi Blender (Kent, 2014) selain dapat membuat benda 3 dimensi, aplikasi ini juga dapat membantu pengguna untuk pipeline-modeling, rigging, animation, simulation, rendering, compositing and motion tracking, even video editing and game creation. Untuk penggunaan yang tingkat lanjut dapat mememasukkan kode dalam Bahasa phyton untuk membuat atau merombak aplikasi ini sendiri.

\subsection{Photo-Realism}

Photorealism adalah genre seni yang mencakup melukis, menggambar dan media grafis lainnya, di mana seorang seniman mempelajari foto dan kemudian mencoba untuk mereproduksi gambar sebagai realistis mungkin di media lain. Karakterisik dari photorealism (Hanusch, 2008) antara lain:
a. Ketidakteraturan (Clutter and Chaos): karakteristik dimana gambar yang dihasilkan tidak sempurna karena setiap benda pasti memiliki cacat.
b. Personality dan Ekspektasi: hasil sesuai dengan ekspektasi yang diharapkan.
c. Believeability: dapat membuat terlihat seperti kondisi nyata.
d. Surface Texture: memiliki pola tekstur di setiap objek permukaan.
e. Specularity: memiliki tingkat refleksi terhadap suatu objek. 
f. Dirt, dust and rust: suatu objek terlihat terdapat efek kotor, debu atau karat.

g. Flaws, Scratches and Dings: objek tertentu memiliki efek pernah mengalami tercakar atau tergesek ataupun pernah dipukul.

h. Beveled Edges: efek sisi yang tidak kaku.

i. Object Material depth: memiliki perpektif tingkat kedalaman.

j. Radiosity: memiliki efek radiasi.

\subsection{Metode}

Pembuatan pemetaan 3 dimensi menggunakan 2 aplikasi yaitu Blender dan Unity 3D, ketika dalam pembentukan objek 3 dimensi dibutuhkan beberapa langkah/metodologi yaitu:

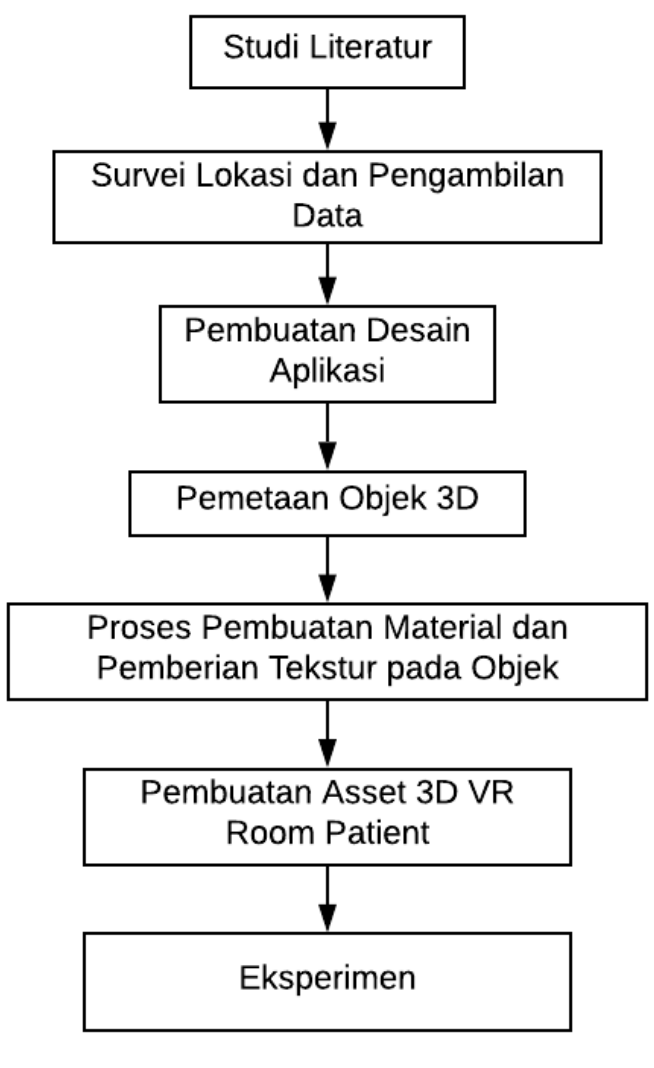

Gambar 1. Metodologi Penelitian

Tahapan pada penelitian ini, diantaranya studi literatur, survei lokasi dan pengambilan data, pembuatan desain aplikasi, pemetaan objek 3D, pembuatan material dan pemberian tekstur pada objek dan pembuatan aset 3D VR Room Patient, dan dilanjutkan percobaan menggunakan photorealism.

2.5.1. Studi Literatur, Survei Lokasi dan Pengambilan Data

Pada tahapan ini, dilakukan dalam mempelajari pengembangan dan pemahaman dari paperpaper sebelumnya, kemudian dilanjutkan survei lokasi penelitian dan pengambilan data, dimana pada tahapan ini dilakukan pengambilan gambar foto dari area lokasi penelitian.

Penelitian ini mengambil area ruang Presidential Suite (Ruang VIP A) pada RSI Jemursari, dimana lokasi tersebut berada di area 1t.1 Gedung Rumah Sakit seperti yang digambarkan pada Gambar 2. 


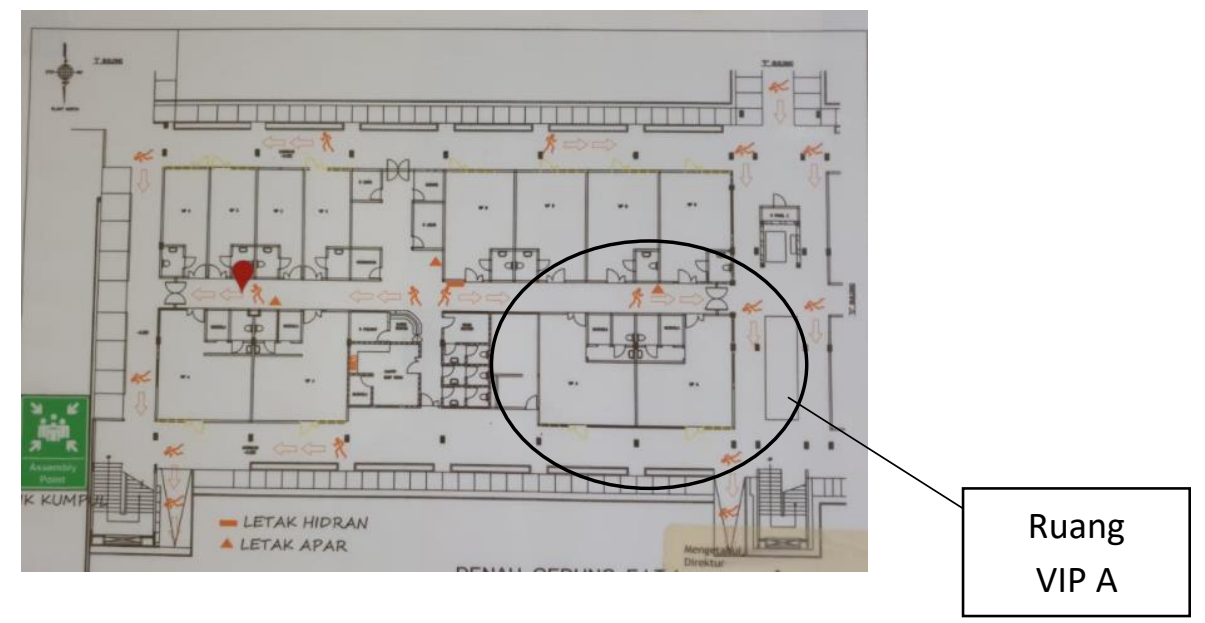

Gambar 2. Lokasi Penelitian VR Patient Room

\subsubsection{Pembuatan Desain Aplikasi}

Pada tahapan ini desain aplikasi digunakan sebagai penunjang proses pembuatan VR-Patient Room dimana didalamnya desain rancangan, penggunaan aplikasi seperti blender dan unity dimana diperlukan juga penggunaan SDK virtual reality. Berikut mapping yang dilakukan dan digambarkan dalam bentuk denah area ruang rawat inap, seperti yang digambarkan pada Gambar 3.

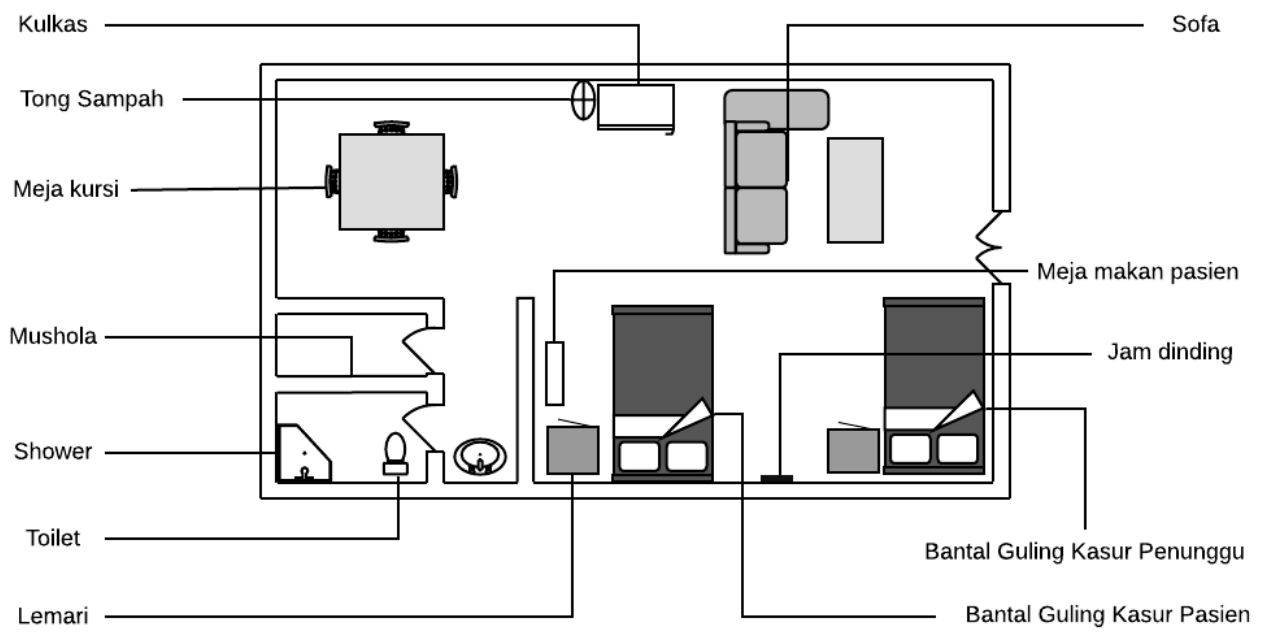

Gambar 3. Denah Area Ruang VIP A

2.5.3. Pemetaan Objek 3D, Pembuatan Material dan Pemberian Tekstur pada Objek

Pada tahapan ini dilakukan pembuatan mapping objek 3D dan pengaturan area objek, pembuatan kerangka objek 3D dan dilakukan proses pemberian material dan penggunaan tekstur pada objek yang dibuat.

\subsubsection{Pembuatan Aset-Object 3D VR Room Patient}

Pada tahapan ini, pembuatan aset berupa kumpulan model objek-objek yang digambarkan dalam bentuk 3D, dilanjutkan dengan proses render objek dan penggabungan berbagai objekobjek yang dibuat sebelumnya kemudian digabungkan sesuai dengan denah area ruang VIP A 
berdasarkan pengambilan gambar blueprint foto. Berikut tabel perbandingan gambar asli dengan hasil objek 3D yang dapat di lihat pada Tabel 1 .

Tabel 1. Tabel perbandingan gambar asli dengan hasil objek 3D.

\begin{tabular}{|l|l|l|l|}
\hline No & Gambar Asli & Detail \\
\hline 1 & & & $\begin{array}{l}\text { Bantal } \\
\text { guling } \\
\text { Kasur } \\
\text { Pasien }\end{array}$ \\
\hline 2 & & & \\
\hline 3 & & & \\
\hline
\end{tabular}




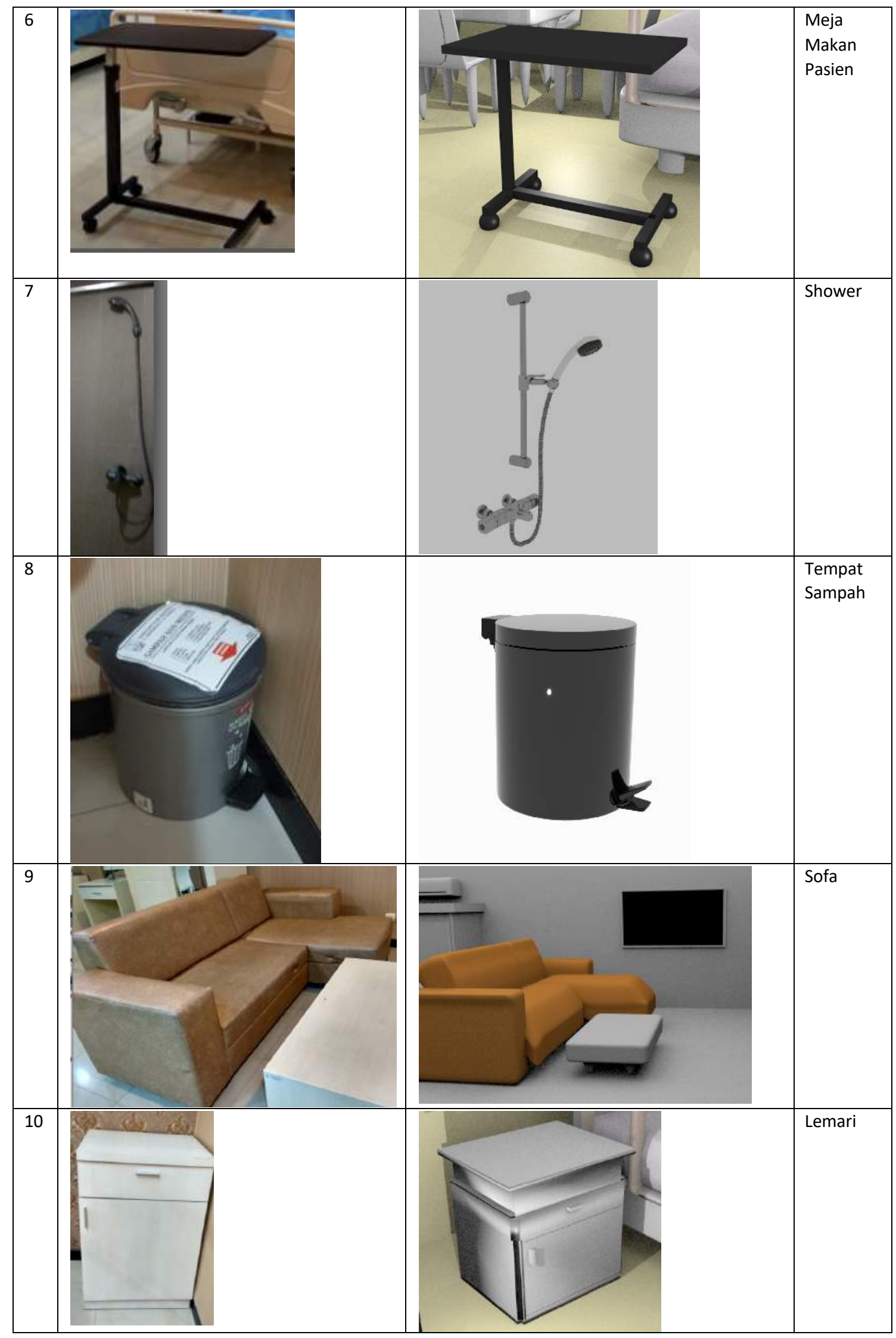




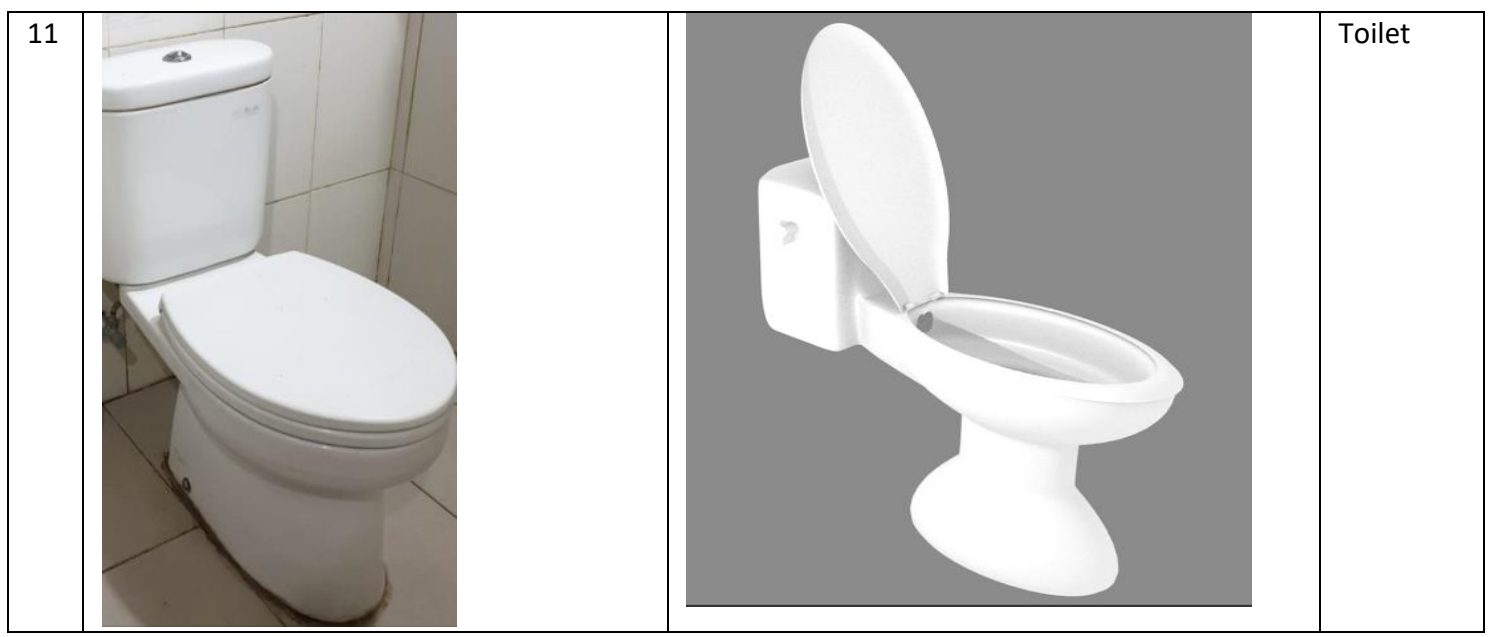

Setelah semua objek-objek dibuat menjadi 3 Dimensi, maka selanjutnya objek-objek tersebut dilakukan append dimana penggabungan aset-objek 3D dengan membuat ruangan rawat inap seperti yang ditunjukkan pada Gambar 4.

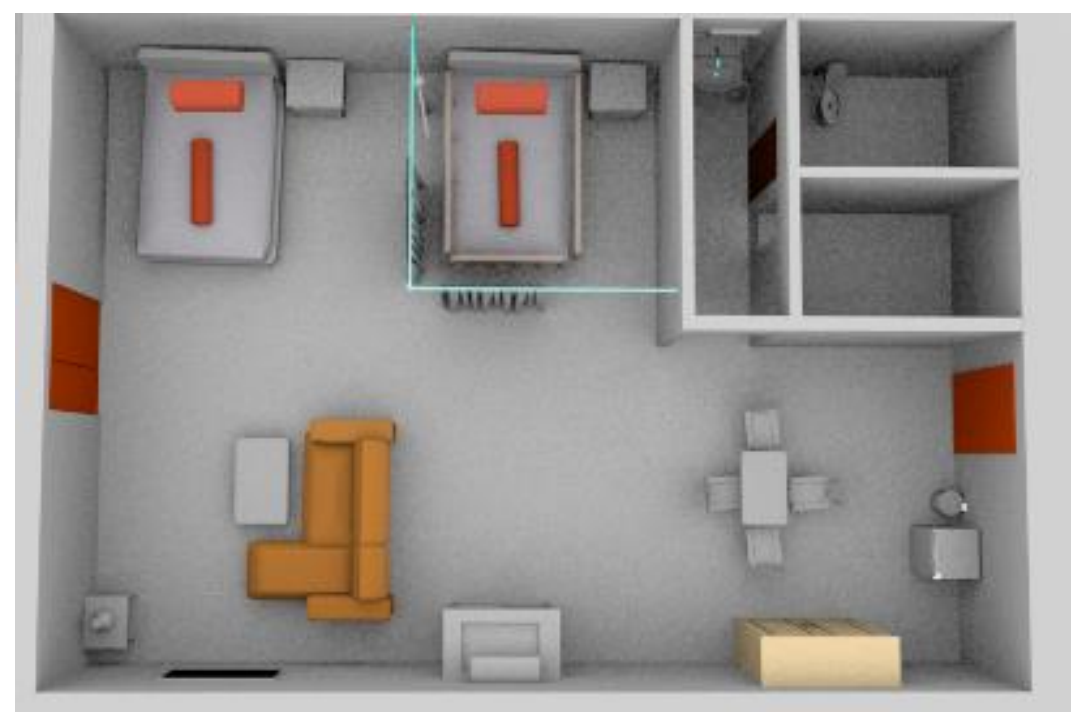

Gambar 4. Penampakan gabungan objek 3D dalam ruangan.

\section{HASIL DAN PEMBAHASAN}

Pada eksperimen ini dilakukan dengan cara melakukan survey kepada 30 responden. Responden diminta untuk menilai masing-masing objek dengan melihat karakteristik dari photorealism. Responden tidak tergantung dari kelamin, usia maupun Pendidikan. Nilai survei terdiri dari buruk sekali/tidak sesuai sama sekali (1), buruk/tidak sesuai (2), cukup (3), baik/sesuai (4), baik sekali, sangat sesuai (5). Dari hasil survei yang dilakukan, didapatkan data hasil eksperimen, sebagai berikut: 
Tabel 2. Hasil survei dari eksperimen.

\begin{tabular}{|c|c|c|c|c|c|c|c|c|c|c|c|c|}
\hline No & Objek & 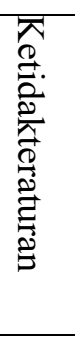 & 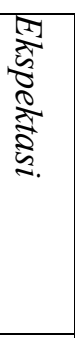 & 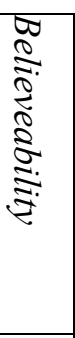 & 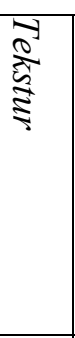 & 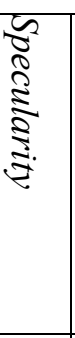 & 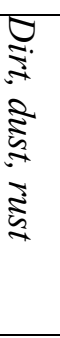 & 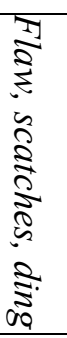 & $\begin{array}{l}\frac{0}{0} \\
\frac{0}{0} \\
0 \\
0 \\
0 \\
0 \\
0 \\
0\end{array}$ & $\frac{\infty}{8}$ & 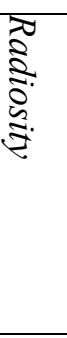 & 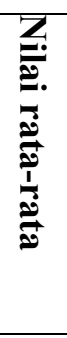 \\
\hline 1 & $\begin{array}{l}\text { Bantal guling Kasur } \\
\text { pasien }\end{array}$ & 4 & 4 & 4 & 4 & 4 & 4 & 3 & 4 & 4 & 3 & 3.8 \\
\hline 2 & $\begin{array}{l}\text { Bantal guling Kasur } \\
\text { penunggu }\end{array}$ & 4 & 4 & 4 & 4 & 4 & 4 & 3 & 4 & 4 & 3 & 3.8 \\
\hline 3 & Jam dinding & 4 & 5 & 4 & 5 & 3 & 4 & 4 & 4 & 4 & 4 & 4.1 \\
\hline 4 & Kulkas & 4 & 4 & 4 & 4 & 4 & 4 & 3 & 4 & 4 & 3 & 3.8 \\
\hline 5 & Meja kursi & 4 & 4 & 4 & 3 & 4 & 4 & 4 & 4 & 4 & 3 & 3.8 \\
\hline 6 & Meja makan pasien & 4 & 4 & 4 & 4 & 4 & 4 & 3 & 4 & 4 & 3 & 3.8 \\
\hline 7 & Shower & 4 & 4 & 4 & 5 & 3 & 4 & 3 & 4 & 4 & 3 & 3.8 \\
\hline 8 & Tempat sampah & 4 & 3 & 4 & 5 & 3 & 4 & 3 & 4 & 4 & 3 & 3.7 \\
\hline 9 & Sofa & 4 & 5 & 4 & 4 & 4 & 4 & 4 & 4 & 4 & 4 & 4.1 \\
\hline 10 & Lemari & 4 & 3 & 4 & 4 & 4 & 4 & 4 & 4 & 4 & 3 & 3.8 \\
\hline 11 & Toilet & 4 & 3 & 4 & 4 & 4 & 4 & 4 & 4 & 4 & 3 & 3.8 \\
\hline
\end{tabular}

Dari hasil survey didapatkan, bahwa tidak ada nilai rata-rata yang dibawah 3,7. Hal ini artinya bahwa objek-objek 3D aset yang dibuat sudah mengikuti unsur photo-realism.

\section{KESIMPULAN}

Berdasarkan hasil eksperimen yang sudah dilakukan maka dapat disimpulkan bahwa:

1. Untuk membuat aplikasi Building Information Management (BIM) berbasis VR diperlukan aset 3D dengan model photorealism.

2. Tingkat photorealism dari masing-masing aset yang dibuat memiliki nilai diatas 3,7 dimana hal ini berarti bahwa objek 3D yang telah dibuat sudah masuk kategori photorealism.

3. Hasil penggabungan objek 3D yang dihasilkan dapat mendukung Denah Ruangan pada Rumah Sakit agar tampak lebih menarik. Namun, untuk kedepannya hasil dari Denah Ruangan ini akan dilakukan integrasi 3D aset dengan perangkat Virtual Reality dengan pembuatan aplikasi VR untuk digunakan secara interaktif.

\section{UCAPAN TERIMA KASIH}

Penelitian ini didanai hibah dari Kementerian Riset, Teknologi, dan Pendidikan Tinggi Republik Indonesia (Ristekdikti) dengan skema Penelitian Dosen Pemula (PDP) pada tahun 2019.

\section{DAFTAR PUSTAKA}

[1] Aditama, D., Budiarti, R.P.N., Nugroho, S.M.S. and Hariadi, M., "Dynamic Evolution Behavior for Non-Player Character on Space Shooter Game Using NSGA-II.,". International Journal of Education and Research., vol.5, no.1., 2017. 
[2] Y. C. C. Y. P. Y. H. W. H. C. Y. \&. S. Y. C. Lin, "Integrated BIM, game engine and VR technologies for healthcare design: A case study in cancer hospital.," Advanced Engineering Informatics, vol. 26, pp. 130-145, 2018.

[3] Dunston, P. S., Arns, L. L., Mcglothlin, J. D., Lasker, G. C., \& Kushner, A. G. An immersive virtual reality mock-up for design review of hospital patient rooms. In Collaborative design in virtual environments, pp. 167-176. Springer, Dordrecht. 2011.

[4] Chan, W.Y. and Tam, H.H. A Virtual Clinical Learning Environment for Nurse Training. In Technology in Education. Innovative Solutions and Practices: Third International Conference, ICTE 2018, Hong Kong, China, January 9-11, 2018, Revised Selected Papers (Vol. 843, p. 16). Springer. 2018.

[5] Jonathan Linowes. "Unity Virtual Reality Projects”. Packt Publishing. 2015.

[6] Pavol Kaleja dan Maria Kozlovska. "Virtual Reality as Innovative Approach to the Interior Designing”, Journal of Civil Engineering Vol. 12, No. 1, 2017.

[7] S. Bayona, "Implementing Virtual Reality in the healthcare sector," searchgate, p. 29, 2016.

[8] Blender 3D. https://www.blender.org/, has accessed, 21 april 2019.

[9] B. R. Kent, "3D scientific visualization with blender"., Morgan \& Claypool Publishers., 2014.

[10] T. Hanusch, "A New Texture Mapping Algorithm For Photorealistic Reconstruction Of 3d Objects," in The International Archives of the Photogrammetry, Remote Sensing and Spatial Information Sciences. Vol. XXXVII. Part B5. Beijing 2008, 2008. 